\title{
Inflammation-mediated Phenoconversion: A Potential Threat to COVID-19 Pharmacotherapy
}

\author{
Muh. Akbar Bahar', Bob Wilffertt ${ }^{2,3}$, Harapan Harapan ${ }^{4,5,6}$, Firzan Nainu ${ }^{1 *}$ \\ ${ }^{1}$ Faculty of Pharmacy, Universitas Hasanuddin, Makassar, Indonesia \\ ${ }^{2}$ Groningen Research Institute of Pharmacy, Department of PharmacoTherapy, Epidemiology and Economics, University of \\ Groningen, Groningen, the Netherlands \\ ${ }^{3}$ Department of Clinical Pharmacy and Pharmacology, University Medical Center Groningen, Groningen, the Netherlands \\ ${ }^{4}$ Medical Research Unit, School of Medicine, Universitas Syiah Kuala, Banda Aceh, Aceh, Indonesia \\ ${ }^{5}$ Tropical Disease Centre, School of Medicine, Universitas Syiah Kuala, Banda Aceh, Aceh, Indonesia \\ ${ }^{6}$ Department of Microbiology, School of Medicine, Universitas Syiah Kuala, Banda Aceh, Aceh, Indonesia
}

\section{ARTICLE INFO}

Article history:

Received October 1, 2020

Received in revised form December 14, 2020

Accepted December 20, 2020

KEYWORDS:

COVID-19,

inflammation,

phenoconversion

\begin{abstract}
One of the important hallmarks of coronavirus disease 2019 (COVID-19) is the existence of severe inflammatory responses. Many reports indicated that inflammatory mediators might suppress the biological functions of some drug metabolizing enzymes and transporters, and therefore result in a transient mismatch between their genotype and phenotype expressions, a phenomenon which is called phenoconversion. The incidence might be clinically relevant to the COVID-19 patients with comorbidities. The patients are treated with multiple drugs that are prone to be altered pharmacokinetically by inflammation-mediated phenoconversion, leading to the modification of their effectiveness and safety. In this review, we discuss the regulation of inflammatory responses during COVID-19 infection and the evidence as well as potential mechanisms of inflammationmediated phenoconversion. We also provide possible clinical implications of such phenoconversion events as a potential threat in the management of COVID-19 patients.
\end{abstract}

\section{Introduction}

In the end of 2019, a number of people in Wuhan, China, were reported to contract pneumonialike illnesses that in some of the infected ones immediately developed into acute respiratory distress syndrome (ARDS) (Huang et al. 2020). The disease, termed officially by WHO as coronavirus disease 2019 (COVID-19) in February 2020, was soon discovered to be linked with a novel infectious agent named as severe acute respiratory syndrome coronavirus 2 (SARS-CoV-2) (Dhama et al. 2020). At present, COVID-19 has been classified as a pandemic with more than 66 million positive cases worldwide (WHO 2020). With such devastating global profile, the emergence of COVID-19 and its suggested causative agent, SARS-CoV-2, has marked an ominous timeline in the history of human modern civilization.

\footnotetext{
* Corresponding Author

E-mail Address: firzannainu@unhas.ac.id

Much has been done at the frontiers to demonstrate the perilous nature of SARS-CoV-2 and COVID-19, the disease it causes (Dhama et al. 2020; Harapan H et al. 2020; Vabret et al. 2020). In parallel, collective global efforts to search for effective COVID-19 vaccines and clinically proven antiviral drugs to combat SARS-CoV-2 have increased our chance to provide safe and sound COVID-19 preventive measures and pharmacological treatments, respectively (Vabret et al. 2020; Corey et al. 2020; Guy et al. 2020). In addition to that, wide-concerted curated efforts to provide the best clinical guidelines for COVID-19 patients have been a remarkable step in response to the COVID-19 pandemic (Tobaiqy et al. 2020; Sanders et al. 2020). However, even with those marvelous endeavors, much remains elusive in terms of our understanding whether currently given drugs can help SARS-CoV-2 infected patients to clear off the viral particles and promote successful recovery from infection.

A further important pharmacological aspect to consider is the occurrence of inflammatory responses in COVID-19 patients that might result in 
the repression of biological activities of some drugmetabolizing enzymes (DMEs) and transporters (Aitken AE et al. 2006; Vabret et al. 2020). The inflammation process might result in a transient phenoconversion phenomenon in which there is a deviation between the function encoded in the genotype and the phenotype expression to some extent (Shah and Smith 2015). This inflammationmediated phenoconversion is particularly important with COVID-19 patients who have comorbidities. These patients might have multiple drug therapies needed to be metabolized and transported by DMEs and transporters which are potentially impacted by inflammation-mediated phenoconversion. In this review, we attempt to discuss the mechanisms of how SARS-CoV-2 can promote inflammatory responses in the infected patients and how such events will potentially result in the emergence of inflammationmediated phenoconversion. In the end, we will address the possible implications of such phenoconversion events in the management of COVID-19 patients, which further shall provide safer and scientifically sound pharmacological interventions.

\section{COVID-19 and Inflammation}

Accumulating evidence has suggested that SARSCoV-2 enters the host cells via ACE2-mediated endocytosis and carry out their replication in the cytoplasm of the infected cells (Hoffmann et al. 2020). After assembling all components required for their replication, the newly produced SARS-CoV-2 particles further relocate into the extracellular space, ready to infect new host cells (Hoffmann et al. 2020; Tang et al. 2020). Just after entering the cells, the presence of SARS-CoV-2 genome in the endosome and/or cytoplasm has been suggested to trigger the activation of innate intrinsic antiviral response in the host cells (Vabret et al. 2020; Tang et al. 2020; Li et al. 2020). Several RNA sensors, for example Toll-like receptors 7 and 8 in the endosome and MDA- 5 and RIG-I in the cytoplasm, are capable to detect RNA viral genome, including SARS-CoV-2 genome, and the activation of these sensors subsequently initiates a series of cascade reactions to stimulate the secretion of proinflammatory cytokines that leads to the recruitment of immune cells to the sites of infection (Vabret et al. 2020; Tang et al. 2020; Li et al. 2020).

In general, the release of pro-inflammatory cytokines into the extracellular regions of infection sites serves as a good indicator for host immune activation upon introduction of foreign particles and pathogens, such as bacteria or viruses, into the host body (Chaplin 2010; Rouse and Sehrawat 2010). In the context of SARS-CoV-2 infection, inflammatory reactions at the sites of infection, including lungs, have been suggested as the results of host innate recognition to certain components of SARS-CoV-2 particles and/or countermeasure responses to robust yet unidentified viral activities in the cytoplasm of the infected cells (Vabret et al. 2020; Li et al. 2020; Vardhana and Wolchok 2020; Tay et al. 2020).

Inflammation is an important response to fend off the invading pathogens (Chaplin 2010; Rouse and Sehrawat 2010). However, it is worth to note that in some cases, a dysregulated inflammatory response posits a serious threat for host cells (Rouse and Sehrawat 2010). Indeed, recent evidence showed that COVID-19 patients, particularly the ones with severe status, experienced hyper-inflammatory responses that have been suggested to lead to multiorgans failure (Huang et al. 2020; Chen et al. 2020). Early reports indicate that inflammation was initiated at the respiratory tracts of the COVID-19 patients and in the severe COVID-19 patients, it soon developed as acute respiratory distress syndrome (Chen et al. 2020). Pathogenic mechanisms on how SARS-CoV-2 causes such fatal syndrome remain largely unknown. However, scientists expect it might be similar to that of SARS-CoV (Vabret et al. 2020; Tay et al. 2020).

Coronavirus replication is likely to activate the host cells defense system that leads to the increased production of antiviral proteins such as interferon and the subsequent release of different types of pro-inflammatory cytokines (Fung and Liu 2019; Li et al. 2020). In the context of COVID-19, levels of pro-inflammatory cytokines, such as interleukins (IL-2, IL-6, IL-7, IL-8, IL-10), tumor necrosis factor (TNF)- $\alpha$, granulocyte colony-stimulating factor (GCSF), interferon gamma-induced protein (IP)-10, monocyte chemoattractant protein (MCP)-1, and macrophage inflammatory protein (MIP)- $1 \alpha$, were reported to increase, especially in ICU (intensive care unit) patients with severe COVID-19, suggesting the possible correlation between increased proinflammatory cytokine levels and COVID-19 severity (Huang et al. 2020; Vabret et al. 2020; Tang et al. 2020; Vardhana and Wolchok 2020; Chen et al. 2020).

Immediate release of pro-inflammatory cytokines can occur due to insults from certain stressors and 
conditions, including the untimely death of virusinfected cells in the absence of swift elimination by phagocytic cells (Rock and Kono 2008; Nainu et al. 2017). In addition to the mechanism described above, the extracellular presence of SARS-CoV-2-related proinflammatory cytokines is triggered by the occurrence of pyroptosis in the macrophages and lymphocytes of COVID-19 patients (Yang 2020). Leakage of dangerassociated molecular patterns (DAMPs) and/or pathogen-associated molecular patterns (PAMPs) from virus-infected cells that undergo pyroptosis, a type of inflammation-related cell death, is a potential way to induce rapid expression of pro-inflammatory cytokines (Bergsbaken et al. 2009; Zhao and Zhao 2020). The formation of NLRP3 (NOD-like receptor protein 3) inflammasome and the rapid secretion of IL-1 $\beta$ in macrophages have been demonstrated in SARS-CoV infection (Chen et al. 2019). While a similar mechanism is subject for demonstration in SARS-CoV-2 infection, the formation of NLRP3 inflammasome has been shown to result in the vast induction of pro-inflammatory cytokines (Bergsbaken et al. 2009). Inflammation is a complex process that can occur via multiple distinct pathways (Chen et al. 2017). In addition to possible immune activation by innate and adaptive recognition to SARS-CoV-2 and the outcome of pyroptotic cell death, inflammatory responses might be induced via the AngiotensinACE2-mediated axis (Bergsbaken et al. 2009; Vabret et al. 2020; Yang 2020). Early reports have suggested that SARS-CoV-2 infects human host cells through ACE2-mediated and TMPRSS2-supported endocytosis (Hoffmann et al. 2020) (Vabret et al. 2020; Yang 2020). This entry mechanism is similar to that of SARS$\mathrm{CoV}$ that eventually leads to the downregulation of ACE2 expression in the infected cells (Li et al. 2003; Wang et al. 2008; Glowacka et al. 2010). Considering that SARS-CoV-2 has been shown to infect host cells through a similar ACE2-dependent viral entry mechanism, it is possible that a similar negative regulation of ACE2 gene expression might occur in the infected host cells. Physiologically, ACE2 plays a vital role in the degradation of Angiotensin II (AngII) into vasoprotective Ang1-7 and Ang 1-9 molecules (Tikellis and Thomas 2012). Reduced expression of pulmonary ACE2 has been reported to result in the increased induction of AngII-mediated inflammation leads to the emergence of fibrosis and lung injury (Imai et al. 2005; Imai et al. 2008; Kuba et al. 2005). Therefore, pathophysiological phenotype for COVID-19 patients may include AngII-associated lung injury, as observed in the SARS-CoV infection (Kuba et al. 2005; Imai et al. 2008). AngII-mediated inflammation accompanied by increased vascular permeability, lung edema, and enhanced penetration of neutrophils to the sites of infection due to the reduced expression of ACE2 have been demonstrated in the acute respiratory disease (ARD) murine model (Imai et al. 2005).

In severe COVID-19 patients, the occurrence of hyper-inflammation as a result of cytokine storm has been suggested (Vabret et al. 2020; Vardhana and Wolchok 2020; Tay et al. 2020). Cytokine storm is a condition where excessive proinflammatory cytokines, for example interleukin(s) and chemokine(s), are produced by the host immune cells in response to foreign insult(s), including in the event of betacoronavirus infection such as SARS-CoV8, MERS-CoV, and possibly SARS-CoV-2 (Tisoncik et al. 2012; Channappanavar and Perlman 2017; Song et al. 2020). Indeed, as a hallmark of severe MERS-CoV infection and to some extent, SARS-CoV-2 infection, elevated levels of certain proinflammatory cytokines, for example IL-6, in the late event of infection have been specifically suggested to correlate with respiratory failure, ARDS, and adverse clinical outcomes (Vabret et al. 2020; Tay et al. 2020; Channappanavar and Perlman 2017; Song et al. 2020). With this in mind, proper induction of inflammation as an antiviral response and subsequent resolution at a given time to limit the immunopathology of inflammatory reactions on the infected patients shall hold critical roles in effort to obtain a better clinical outcome.

\section{Inflammation-Mediated Phenoconversion: Evidence and Mechanisms}

Mounting non-clinical and clinical evidence have shown that elevated production of some proinflammatory cytokines (such as IL-1, IL-6, IFN or, TNF) during the inflammation process potentially alters the genetic modulation of some DMEs, reduces their hepatic levels, and therefore, decreases their metabolic activities (Aitken et al. 2006; Shah and Smith 2015; Storelli et al. 2018). This condition might lead to a transient phenoconversion of DMEs, which is defined as a discordance between their genotypic status (normal metabolizer/NM) and their phenotypic expression (intermediate metabolizer/IM or poor metabolizer/PM). It was estimated that the metabolic 
clearance of some drugs was reduced substantially by 20 to $70 \%$ in inflammation state (Aitken et al. 2006). It seems that although the genotype status of the responsible DMEs corresponds to normal metabolic function, their phenotypic expressions might differ during inflammatory conditions. Therefore, phenoconversion of DMEs might potentially impact the drug efficacy and safety if it is not well recognized and managed clinically.

In vitro experiments by incubation of proinflammatory cytokines with rodents and human hepatocytes cultures showed that the cytokines were able to downregulate some cytochrome P450 (CYP450) biosynthesis (Sunman et al. 2004; Aitken et al. 2006; Shah and Smith 2015). Likewise, experimental inflammatory or infection models which were developed by inoculation of bacterial, viral, parasitic, or other inflammatory inducers (such as cytokines, interferons, irritants, or adjuvants) indicated that increased exposure to inflammatory cytokines led to the decrease of the total amount of hepatic CYP450 (CYP) expressions and their metabolic activities were markedly reduced (Sewer et al. 1997; Siewert et al. 2000; Aitken et al. 2006; Shah and Smith 2015). The reduction rate of mRNA expression of some CYP isoenzymes was in line with the increase in the production of pro-inflammatory cytokines. Comprehensive reviews on the in vitro and in vivo studies on the inflammation-mediated CYP depression can be read elsewhere (Aitken et al. 2006; Morgan et al. 2011; Shah and Smith 2015).

In terms of clinical studies, the first notable case on the clinical impact of inflammation on drug biotransformation was observed during the influenza B epidemic in Washington, US, in 1980 (Kraemer et al. 1982). Eleven young asthmatic patients who used theophylline routinely as a maintenance treatment developed theophylline related toxicities, such as convulsions, gastrointestinal disturbances, and headache, because of the elevated blood concentration of theophylline (Kraemer et al. 1982). Alteration of metabolic clearance of theophylline was assumed as the culprit (Kraemer et al. 1982). Theophylline is extensively metabolized by CYP1A2 enzyme in the liver and therefore, influenza $B$ infection was considered to decrease the metabolic activity of the enzyme. The comparable condition was found previously in patients treated with theophylline who were infected with influenza A (Chang et al. 1978). Patients with viral upper respiratory infection were reported to have a prolonged half-life of theophylline, which was assumed to be due to a decrease in the catalytic activity of the drug-metabolizing enzyme (Chang et al. 1978). Shedlofsky et al. 1994 confirmed the hypothesis by doing an experiment in which they injected lipopolysaccharide (LPS) to healthy male volunteers to induce acute inflammation, who were then administered with theophylline (Shedlofsky et al. 1994). As expected, LPC induced the increased of TNFA, IL-1ß, and IL-6 blood levels and caused a $22 \%$ decrease in theophylline clearance (Shedlofsky et al. 1994).

Another clinical example of the effects of inflammation-mediated reduction of CYP metabolic capacity can be observed in sepsis children treated with antipyrine (Carcillo et al. 2003). It was found that there was at least two times a reduction of antipyrine metabolic clearance in patients with sepsis compared to the healthy control group (Carcillo et al. 2003). The substantial trend of reduction was negatively correlated with the amount of IL- 6 as well as the level of nitric oxide (NO) production in the blood (Carcillo et al. 2003). Antypirine is metabolized by several CYP sub-families such as CYP1A2, CYP2B6, CYP2C8, CYP2C9, CYP2C18, and CYP3A4 (Engel et al. 1996). Therefore, there was a possibility that elevated levels of cytokines during inflammation as well as the increase of NO levels may suppress the catalytic activities of those CYP enzymes.

A next clinical example was reported in rheumatoid arthritis (RA) patients who used simvastatin (a CYP3A4 subsrate) (Lee et al. 2017). It was reported that during simvastatin treatment, RA patients had a significant increase of simvastatin area under curve (AUC) [84.3 ng.h/ml $(S D=53.6)]$ compared to the reference value reported in healthy individuals (17-50 $\pm 10-22 \mathrm{ng} . \mathrm{h} /$ $\mathrm{ml}$ ) (Lee et al. 2017). RA patients commonly have an elevated circulating IL-6, and therefore potentially have a depressed CYP3A4 metabolic activity due to IL-6 actions. Interestingly, the co-administration of sarilumab (a human monoclonal antibody which works by blocking IL-6R $\alpha$ ) could return the AUC of simvastatin to the normal concentration [ $47.9 \mathrm{ng} . \mathrm{h} / \mathrm{ml}$ ( $S D=33.4)$ ] (Lee et al. 2017). It indicated that IL-6 plays an important role in depressing the activity of CYP3A4 and the transient decrease of CYP3A4 metabolic activity could be normalized by IL- 6 inhibitor administration. It was estimated that inflammation might reduce the CYP3A4 metabolic activity by 20 to $60 \%$ (Haas et al. 2003). An equivalent scenario was 
also reported in the interaction between sirukumab (another human IL-6 blocker monoclonal antibody) with several CYP substrates such as midazolam (a CYP3A substrate), omeprazole (a CYP2C19 substrate), and warfarin (a CYP2C9 substrate) in RA patients (Zhuang et al. 2015). The high systemic level of IL-6 in RA condition seemed to downregulate the CYP enzymes, resulting in the higher blood concentration of midazolam, omeprazole, and warfarin than in normal persons (Zhuang et al. 2015). However, after a single administration of sirukumab, there was a decrease in the level of midazolam, omeprazole, and warfarin exposures by $30-35 \%, 37-45 \%$, and $18-$ $19 \%$, respectively, to the level of exposures in the normal condition (Zhuang et al. 2015). The results were aligned with the idea that IL- 6 has an ability to transiently suppress metabolic activities of some CYP sub-families which can be conversed by an IL-6 blocker.

Another important CYP subtype that is potentially depressed by cytokines is CYP2D6. It was reported that CYP2D6 catalytic activity was decreased by about $90 \%$ in persons with HIV compared to the normal control (Jones et al. 2010). It was also noted that about $25 \%$ of patients experienced phenoconversion in which they were genetically NM but phenotypically PM (Jones AE et al. 2010). The CYP2D6 activity was inversely correlated with the blood concentration of TNF $\alpha$ (Jones $\mathrm{AE}$ et al. 2010). Interestingly, from the same study, it was also found that the activity of $\mathrm{N}$-acetyltransferase 2 (NAT2), a phase II drug metabolizing enzyme, was also lessened by $53 \%$ compared to the healthy individuals and results in a significant phenotypic conversion from fast to slow acetylation (Jones AE et al. 2010). The rate of phenoconversion is associated with the progression of HIV disease (Jones AE et al. 2010; Shah and Smith 2015). However, the overall impact of inflammation on metabolic capacities of Phase II drug metabolizing enzymes generally has not been comprehensively explored yet (Aitken et al. 2006).

The molecular mechanisms of inflammationmediated phenoconversion are still not well elucidated. However, there have been some mechanisms proposed to explain how the pro-inflammatory cytokines might suppress the amount and catalytic functions of CYP enzymes. Firstly, the release of proinflammatory cytokines might alter the regulation of some particular transcription factors, such as pregnane $X$ receptor (PXR), constitutive androstane receptor (CAR), retinoid $X$ receptor ( $R X R)$, hepatocyte nuclear factor (HNF), nuclear factor- $\kappa \mathrm{B}(\mathrm{NF}-\kappa \mathrm{B})$, and CCAAT/enhancer-binding protein beta $(C / E B P \beta)$, in the liver (Aitken et al. 2006; Morgan et al. 2011). These modifications might lead to a repression of some CYP450 genes transcription, reducing the particular CYP mRNA levels and resulting in the decrease of respective CYP metabolic activities. Secondly, the chronic generation of the pro-inflammatory cytokines might induce nitric oxide synthase 2 (NOS2) to produce hepatic NO (Aitken et al. 2006). NO was reported to potentially down-regulate the expression of CYP genes because it has a capability in modulating HNF4 and NFKB through the formation of S-nitrosylation (cysteine-nitrosylation) on the DNAbinding domains of the transcription factors (Aitken et al. 2006; Morgan et al. 2011). Additionally, NO was also indicated to be able to decrease the metabolic activity of hepatic CYP enzymes by nitrosylation of cysteine or tyrosine residues in the various CYP structure (Aitken et al. 2006; Morgan et al. 2011).

Furthermore, inflammation was also reported to influence the function of main drug transporter such as P-glycoprotein (P-gp) transporter by suppressing its mRNA expression as well as its biological activity (Aitken et al. 2006; Morgan et al. 2011). In vivo models of acute inflammatory conditions, which were created by administration of chemical (turpentine oil) and biological (endotoxin) substances to induce the release of inflammatory cytokines, indicated the substantial decrease in the amount of Mdr1 (Abcb1) gene expression in the liver (gene responsible for encoding P-gp transporter) (Piquette-Miller et al. 1998; Hartmann et al. 2005; Aitken et al. 2006; Morgan et al. 2011). Hartmann et al. 2005 reported a reduction in the systemic clearance of doxorubicin (a P-gp substrate), which led to a significant increase in the AUC of doxorubicin in the LPS-induced acute inflammatory model (Hartmann et al. 2005). Doxorubicin is cleared primarily via biliary secretion which is facilitated by P-gp transporter. Therefore, the reduction of hepatic P-gp level due to inflammation can decrease its clearance from the blood.

It was estimated that there was about $50 \%$ to $70 \%$ reduction of hepatic expression and activity of the drug transporter within one or two days after a chemical irritant injection (Piquette-Miller et al. 1998). The alteration was seemingly produced by a repression of Mdr1a and Mdr1b (isoforms of Mdr1 in mice) nuclear gene transcription via modulation of 
PXR and CAR expression (Sukhai et al. 2000; Morgan et al. 2011). From the in vitro and in vivo studies, Il-6 and IL- $1 ß$ have been identified as the main actors in this cytokines-mediated downregulation of P-gp transporter (Morgan et al. 2011). Alteration of the P-gp transporter might produce a substantial change in the blood concentration of P-gp substrates.

\section{Potential Clinical Implication of Inflammation-Mediated Phenoconversion in COVID-19}

As mentioned above, inflammation might reduce metabolic activities of a wide range of important CYP enzymes such as CYP1A2, CYP2B6, CYP2C8, CYP2C9, CYP2C19, CYP2D6, CYP2C18, and CYP3A4. Altogether, these CYP enzymes metabolize about $90 \%$ of drugs used in clinical settings (Zanger and Schwab 2013). Additionally, inflammation is also reported to influence the activities of Phase II drug metabolizing enzymes as well as P-gp drug transporter (Aitken et al. 2006; Morgan et al. 2011). Therefore, pharmacokinetics of drugs used by COVID-19 patients have a high probability to be altered by inflammation-mediated phenoconversion to some extent.

Patients with COVID-19 experiencing severe conditions because of cytokine storms, are not uncommon to have comorbidities (Guan et al. 2020; Richardson et al. 2020). Several frequent diseases observed among COVID-19 patients are hypertension, coronary artery disease, obesity, diabetes, and chronic respiratory diseases (asthma, COPD) (Guan et al. 2020; Richardson et al. 2020). Consequently, these particular patients might consume several drugs concomitantly. In table 1 , we provide some lists of drugs which are theoretically used by COVID-19 patients and their clinical impacts are potentially altered by inflammation-mediated phenoconversion. If COVID-19 patients are prescribed with normal doses of drugs intended to treat their co-existing comorbidities, their phenoconversion condition might potentially alter the clinical impacts of the drugs either by increasing the risk of side effects because of the elevated plasma concentrations of the drugs or inducing ineffectiveness in case of pro-drugs.

There are some conditions which are theoretically prone to be clinically affected by inflammationmediated phenoconversion such as: 1) elderly patients which normally experience physiologicalrelated changes such as decreased kidney and hepatic functions; 2) patients with pre-existing renal and liver diseases; 3 ) inflammation-mediated phenoconversion affecting not only the main metabolic pathway of the drug but also its alternative metabolic pathway; 4) decreased function of metabolic pathways because of genetic polymorphisms; 5) concomitant use of a drug which is an inhibitor of the DME or transporter; 6) patients using a drug with a narrow therapeutic index. It is therefore important for clinicians to be able to identify patients who are sensitive to be affected by inflammation-mediated phenoconversion as well as to identify potentially affected drugs. It is also prudent that the clinical practitioners are being aware of the potential impact of inflammation-mediated phenoconversion and therefore could do a close monitoring to the potential side effects of particular drugs and if needed, to adjust the dose of the drugs.

Yet, the impact of inflammation-mediated phenoconversion is probably hard to observe clinically since most drugs do have a wide therapeutic index and are commonly metabolized by several metabolic pathways. It has been reported that the failure of one metabolic pathway could be compensated by an alternative metabolic pathway (Bahar et al. 2017). Moreover, the presence of observable impact of side effects due to the increase of drug concentrations might also be shadowed by the COVID-19 symptoms or attributed to the COVID-19 infection.

Another challenge to tackle the potential hazard of inflammation-mediated phenoconversion is the lack of guideline to manage this particular drugdisease interaction. The current guidelines of drug interactions have not considered the importance of inflammation-mediated phenoconversion on drug safety yet. It is understandable since clinical studies regarding the topic is still limited and hard to translate to clinically actionable medication management. Yet, Van Tongeren et al. (2020) have recently published a standardized guideline to help the translation of the available clinical information of drug-disease interactions to applicable clinical action (Van Tongeren et al. 2020).

Nevertheless, exploration of the clinical relevance of inflammation-mediated phenoconversion should still be further pursued. Since patients with comorbidities are commonly not included in randomized clinical trials, the evidence regarding the potential impact of drug-disease interactions is often lacking (Van Tongeren et al. 2020). Therefore, we need an alternative method that can be used 
Table 1. List of drugs which are theoretically used by COVID-19 patients with comorbidities and potentially affected by inflammation mediated phenoconversion (Flockhart 2008; Wishart et al. 2018)

\begin{tabular}{|c|c|c|c|c|}
\hline \multirow{2}{*}{$\begin{array}{l}\text { Drug metabolizing } \\
\text { enzymes and } \\
\text { transporter }\end{array}$} & \multicolumn{4}{|c|}{ Potentially affected drugs } \\
\hline & $D M$ & Hypertension & Coronary Artery disease & $\begin{array}{c}\text { Chronic respiratory } \\
\text { diseases (asthma, COPD) }\end{array}$ \\
\hline CYP2C19 & & Labetalol & $\begin{array}{l}\text { Clopidogrel, labetalol, } \\
\text { coumarins }\end{array}$ & \\
\hline СYР2C9 & $\begin{array}{l}\text { Glibenclamide, } \\
\text { glimepiride, } \\
\text { glipizide, } \\
\text { glyburide, } \\
\text { nateglinide, } \\
\text { rosiglitazone, } \\
\text { tolbutamide }\end{array}$ & $\begin{array}{l}\text { Irbesartan, } \\
\text { losartan }\end{array}$ & Fluvastatin, warfarin & Zafirlukast \\
\hline CYP2D6 & & $\begin{array}{l}\text { Metoprolol, } \\
\text { alprenolol, } \\
\text { carvedilol, } \\
\text { propranolol, } \\
\text { nebivolol, } \\
\text { clonidine }\end{array}$ & $\begin{array}{l}\text { Metoprolol, carvedilol, } \\
\text { propranolol }\end{array}$ & \\
\hline CYP3A4 & $\begin{array}{l}\text { Pioglitazone, } \\
\text { saxagliptin, } \\
\text { sitagliptin, } \\
\text { linagliptin, } \\
\text { canagliflozin, } \\
\text { nateglinide }\end{array}$ & $\begin{array}{l}\text { Amlodipine, } \\
\text { diltiazem, } \\
\text { eplerenone, } \\
\text { felodipine, } \\
\text { lercanidipine, } \\
\text { nifedipine, } \\
\text { nisoldipine, } \\
\text { nitrendipine, } \\
\text { verapamil }\end{array}$ & $\begin{array}{l}\text { Simvastatine, } \\
\text { lovastatine, } \\
\text { amlodipine, } \\
\text { diltiazem, } \\
\text { atorvastatine, } \\
\text { cilostazole, } \\
\text { diltiazem, } \\
\text { felodipine, } \\
\text { nifedipine, } \\
\text { verapamil }\end{array}$ & $\begin{array}{l}\text { Roflumilast, } \\
\text { astemizole, } \\
\text { deflazacort, } \\
\text { salmeterol }\end{array}$ \\
\hline CYP1A2 & & $\begin{array}{l}\text { Verapamil, } \\
\text { propranolol }\end{array}$ & $\begin{array}{l}\text { Verapamil, } \\
\text { propranolol }\end{array}$ & $\begin{array}{l}\text { Theophylline, } \\
\text { roflumilast, zileuton }\end{array}$ \\
\hline СYР2С8 & $\begin{array}{l}\text { Pioglitazone, } \\
\text { Rosiglitazone, } \\
\text { Repaglinide }\end{array}$ & & & Montelukast \\
\hline $\begin{array}{l}\text { CYP2C18 } \\
\text { CYP2B6 }\end{array}$ & Tolbutamide & Verapamil & Verapamil & \\
\hline $\begin{array}{l}\text { CYP2B6 } \\
\text { P-gp transporter }\end{array}$ & $\begin{array}{l}\text { Sitagliptin, } \\
\text { dapagliflozin }\end{array}$ & $\begin{array}{l}\text { Verapamil, } \\
\text { nifedipine, } \\
\text { nicardipine, } \\
\text { prazosin, } \\
\text { diltiazem, } \\
\text { losartan, } \\
\text { clonidine, } \\
\text { propranolol, } \\
\text { amlodipine, } \\
\text { bisoprolol }\end{array}$ & $\begin{array}{l}\text { Coumarins } \\
\text { Dabigatran, verapamil, } \\
\text { nifedipine, } \\
\text { nicardipine, } \\
\text { diltiazem, } \\
\text { simvastatine, } \\
\text { lovastatine, } \\
\text { atorvastatine, } \\
\text { pravastatin, } \\
\text { ticagrelor, Apixaban, } \\
\text { clopidogrel, } \\
\text { propranolol, } \\
\text { amlodipine, } \\
\text { bisoprolol }\end{array}$ & $\begin{array}{l}\text { Fexofenadine, } \\
\text { prednisone, } \\
\text { prednisolone, } \\
\text { methylprednisolone, } \\
\text { beclomethasone } \\
\text { dipropionate, } \\
\text { fluticasone, } \\
\text { revefenacin, } \\
\text { budesonide, } \\
\text { triamcinolone, } \\
\text { cetirizine }\end{array}$ \\
\hline
\end{tabular}

to predict the clinical impact of inflammation on drug pharmacokinetics. One method that could be employed is a physiologically based pharmacokinetic (PBPK) modeling (Jones and Rowland-Yeo 2013). The quantitative biosimulation method can incorporate complex data which are predicted to affect drug pharmacokinetics such as drug-specific parameters as well as variability in internal and external characteristics of the individual patient (Jones and Rowland-Yeo 2013; Vieira et al. 2014). The model has been successfully utilized to predict the magnitude of complex drug interactions (Storelli et al. 2019). 
Finally, the potential impact of inflammation on drug therapy during COVID-19 should be considered concomitantly with other intrinsic (such as genetics, comorbidity: renal disease or liver problems, physiological factors: age, gender and BMI) and extrinsic factors (such as herbal medicine, vitamins and dietary supplement, co-administered drug, and lifestyles: cigarette smoking, exercising, drinking alcohol) which might modify the safety and effectiveness of the drug. The co-existence of internal (genetic polymorphisms, comorbidity) and external (co-medication) factors may produce a complex interaction such as drug-drug-gene-disease interactions/DDGDIs (the overlapping condition of drug-drug-interaction, genetic polymorphisms, and disease) (Storelli et al. 2018). The DDGIs, which may produce a wider range of inter-individual variability on drug exposures than drug-drug interactions and drug-gene interactions, were observed in clinical practice (Storelli et al. 2018). Therefore, a clinical decision support system, which is commonly used to help healthcare professionals in managing drug interactions, should be created to be able to accommodate and process all the clinically relevant information in order to generate a personalized clinical practice to manage potential drug-related problems based on specific risk factors found in patients (Bahar 2020).

\section{Conclusion}

COVID-19 patients are often accompanied with chronic inflammation, a condition which might influence the pharmacokinetics of some drugs prescribed for them via alteration of drug metabolizing enzymes and transporters. Therefore, it is prudent that clinicians (prescribing doctors and pharmacists) should be aware on this drug-disease interaction to minimize the potential harm since inflammationmediated phenoconversion might become an important threat in the COVID-19 management and pharmacotherapy.

\section{Conflict of Interest}

No conflicts are declared.

\section{References}

Aitken AE et al. 2006. Regulation of drug-metabolizing enzymes and transporters in inflammation. Annu Rev Pharmacol Toxicol 46:123-149.

Bahar MA et al. 2017. Pharmacogenetics of drug-drug interaction and drug-drug-gene interaction: a systematic review on CYP2C9, CYP2C19 and CYP2D6. Pharmacogenomics 18:701-739.
Bahar A. 2020. Towards Personalized Management of Drug Interactions: from Drug-Drug-Interaction to DrugDrug-Gene-Interaction. Groningen: University of Groningen.

Bergsbaken T et al. 2009. Pyroptosis: host cell death and inflammation. Nature Reviews Microbiology 7:99-109.

Carcillo JA et al. 2003. Cytochrome P450 mediated-drug metabolism is reduced in children with sepsisinduced multiple organ failure. Intensive Care Medicine 29:980-984.

Chang K et al. 1978. Altered theophylline pharmacokinetics during acute respiratory viral illness. The Lancet 311:1132-1133.

Chaplin DD. 2010. Overview of the immune response.Journal of Allergy and Clinical Immunology 125:3-23.

Chen Let al. 2017. Inflammatory responses and inflammationassociated diseases in organs. Oncotarget 9:72047218.

Channappanavar R, Perlman S. 2017. Pathogenic human coronavirus infections: causes and consequences of cytokine storm and immunopathology. Seminars in Immunopathology 39:529-539.

Chen I et al. 2019. Severe acute respiratory syndrome coronavirus viroporin $3 a$ activates the NLRP3 inflammasome. Frontiers in Microbiology 10:50. DOI:10.3389/fmicb.2019.00050

Chen $\mathrm{G}$ et al. 2020. Clinical and immunological features of severe and moderate coronavirus disease 2019. The Journal of Clinical Investigation 130:2620-2629.

Corey Let al. 2020. A strategic approach to COVID-19 vaccine $\mathrm{R}$ and D. Science 368:948-950.

Dhama K et al. 2020. Coronavirus disease 2019 - COVID-19. Clinical Microbiology Reviews 33:e00028-20.

Engel G et al. 1996. Antipyrine as a probe for human oxidative drug metabolism: Identification of the cytochrome P450 enzymes catalyzing 4-hydroxyantipyrine, 3-hydroxymethylantipyrine, and norantipyrine formation. Clinical Pharmacology and Therapeutics 59:613-623.

Flockhart D. 2018. Drug Interactions Flockhart Table ${ }^{\mathrm{TM}}$. Available at: https://drug-interactions.medicine.iu.edu/MainTable. aspx [Date accessed: 17 July 2020]

Fung TS, Liu DX. 2019. Human coronavirus: host-pathogen interaction. Annual Review of Microbiology 73:29-557.

Guan WJ et al. 2020 and China Medical Treatment Expert Group for COVID-19. Comorbidity and its impact on 1590 patients with COVID-19 in China: a nationwide analysis. The European Respiratory Journal 55:2000547. DOI:10.1183/13993003.00547-2020

Glowacka I et al. 2010. Differential downregulation of ACE2 by the spike proteins of severe acute respiratory syndrome coronavirus and human coronavirus NL63. Journal of Virology 84:1198-1205.

Guy RK et al. 2020. Rapid repurposing of drugs for COVID-19. Science 368:829-830.

Haas CE et al. 2003. Cytochrome P450 3A4 activity after surgical stress. Critical Care Medicine 31:1338-1346.

Harapan Het al. 2020. Coronavirus disease 2019 (COVID-19): a literature review. Journal of Infection and Public Health 13:667-673.

Hartmann G et al. 2005. Impact of endotoxin-induced changes in P-glycoprotein expression on disposition of doxorubicin in mice. Drug Metabolism and Disposition: the biological fate of chemicals 33:820-828.

Hoffmann M et al. 2020. SARS-CoV-2 cell entry depends on ACE2 and TMPRSS2 and is blocked by a clinically proven protease inhibitor Cell 18:271-280.

Huang C et al. 2020. Clinical features of patients infected with 2019 novel coronavirus in Wuhan, China. The lancet 395:497-506.

Imai Y et al. 2005. Angiotensin-converting enzyme 2 protects from severe acute lung failure. Nature 436:112-116. 
Imai Y et al. 2008. The discovery of angiotensin-converting enzyme 2 and its role in acute lung injury in mice. Experimental Physiology 93:543-548.

Jones AE et al. 2010. Variability in drug metabolizing enzyme activity in HIV-infected patients. European Journal of Clinical Pharmacology 66:475-485.

Jones H, Rowland-YeoK.2013. Basic concepts in physiologically based pharmacokinetic modeling in drug discovery and development. CPT: pharmacometrics and systems pharmacology 2:1-12.

Kuba K et al. 2005. A crucial role of angiotensin converting enzyme 2 (ACE2) in SARS coronavirus-induced lung injury. Nature Medicine 11:875-879.

Kraemer MJ et al. 1982. Altered theophylline clearance during an influenza B outbreak. Pediatrics 69:476-480.

Lee EB et al. 2017. Diseaseâ-drug interaction of sarilumab and simvastatin in patients with rheumatoid arthritis. Clinical Pharmacokinetics 56:607-615.

Li W et al. 2003. Angiotensin-converting enzyme 2 is a functional receptor for the SARS coronavirus. Nature 426:450-454.

Li Get al. 2020. Coronavirus infections and immune responses. Journal of Medical Virology 92:424-432.

Morgan ET et al. 2011. Regulation of drug metabolizing enzymes and transporters in infection, inflammation, and cancer. Encyclopedia of Drug Metabolism and Interactions 36:205-216.

Nainu $\mathrm{F}$ et al. 2017. Induction of apoptosis and subsequent phagocytosis of virus-infected cells as an antiviral mechanism. Frontiers in Immunology 8:1220, 2017.

Piquette-Miller $M$ et al. 1998. Decreased expression and activity of P-Glycoprotein in rat liver during acute inflammation. Pharmaceutical Research 15:706-711.

Richardson S et al. 2020. Presenting characteristics, comorbidities, and outcomes among 5700 patients hospitalized with COVID-19 in the New York City area. JAMA 323:2052-2059.

Rock KL, Kono H. 2008. The inflammatory response to cell death. Annu Rev Pathol Mech Dis 3:99-126.

RouseBT,SehrawatDS.2010.Immunity and immunopathology to viruses: what decides the outcome?. Nature reviews Immunology 10: 514-526.

Sanders JM et al. 2020. Pharmacologic treatments for coronavirus disease 2019 (COVID-19): a review.Jama 323:824-1836

Sewer MB et al. 1997. Differential inductive and suppressive effects of endotoxin and particulate irritants on hepatic and renal cytochrome P-450 expression. The Journal of Pharmacology and Experimental Therapeutics 280:1445-1454.

Shedlofsky SI et al. 1994. Endotoxin administration to humans inhibits hepatic cytochrome P450-mediated drug metabolism. The Journal of Clinical Investigation 94:2209-2214

Shah RR, Smith RL. 2015. Inflammation-induced phenoconversion of polymorphic drug metabolizing enzymes: hypothesis with implications for personalized medicine. Drug Metabolism and Disposition: the biological fate of chemicals 43:400-410.

Siewert E et al. 2000. Hepatic cytochrome P450 downregulation during aseptic inflammation in the mouse is interleukin 6 dependent. Hepatology 32:49-55.

Song P et al. 2020. Cytokine Storm Induced by SARS-CoV-2. Clinica Chimica Acta 509:280-287.

Storelli F et al. 2018. Complex drug-drug-gene-disease interactions involving cytochromes P450: systematic review of published case reports and clinical perspectives. Clinical Pharmacokinetics 57:1267-1293.
Storelli F et al. 2019. Physiologically-based pharmacokinetic modeling for the prediction of CYP2D6-mediated gene-drug-drug interactions. CPT: pharmacometrics and Systems Pharmacology 8:567-576.

Sukhai M et al. 2000. Inflammation and interleukin-6 mediate reductions in the hepatic expression and transcription of the mdr1 $a$ and mdr1b genes. Molecular Cell Biology Research Communications 4:248-256.

Sunman JA et al. 2004. Kupffer cell-mediated IL-2 suppression of CYP3A activity in human hepatocytes. Drug metabolism and disposition: the biological fate of chemicals 32:359-363.

Tang D et al. 2020. The hallmarks of COVID-19 disease. Plos Pathogens 16:e1008536. DOI:10.1371/journal. ppat.1008536

Tay MZ et al. 2020. The trinity of COVID-19: immunity, inflammation and intervention. Nature Reviews Immunology 20:363-374.

Tikellis C, Thomas M. 2012. Angiotensin-converting enzyme 2 (ACE2) is a key modulator of the renin angiotensin system in health and disease. International Journal of Peptides 2012:1-8.

Tisoncik JR et al. 2012. Into the eye of the cytokine storm. Microbiol Mol Biol Rev 76:16-32.

Tobaiqy M et al. 2020. Therapeutic management of COVID-19 patients: a systematic review. Infection Prevention in Practice 2:100061. DOI:10.1016/j.infpip.2020.100061

Vabret $\mathrm{N}$ et al. 2020. Immunology of COVID-19: current state of the science. Immunity 52:910-941.

Vieira MDL et al. 2014. PBPK model describes the effects of comedication and genetic polymorphism on systemic exposure of drugs that undergo multiple clearance pathways. Clinical Pharmacology and Therapeutics 95:550-557.

Van Tongeren JM et al. 2020. The development of practice recommendations for drug-disease interactions by literature review and expert opinion. Frontiers in Pharmacology 11:707. DOI:10.3389/fphar.2020.00707

Vardhana SA, Wolchok JD. 2020. The many faces of the antiCOVID immune response. Journal of Experimental Medicine 217:e20200678. DOI:10.1084/jem.20200678

Wang $\mathrm{H}$ et al. 2008. SARS coronavirus entry into host cells through a novel clathrin-and caveolae-independent endocytic pathway. Cell Research 18:290-301.

[WHO] World Health Organization. 2020. Coronavirus disease 2019 (COVID-19): situation report, 88.

Wishart DS et al. 2018. DrugBank 5.0: a major update to the DrugBank database for 2018. Nucleic Acids Research. 46:1074-1082.

Yang M. 2020. Cell Pyroptosis, A Potential Pathogenic Mechanism of 2019-nCoV Infection. Available at: https://ssrn.com/abstract=3527420 [Date accessed: 20 June 2020]

Zhao C, Zhao W. 2020. NLRP3 Inflammasomeâ€"A key player in antiviral responses. Frontiers in Immunology 11:211. DOI:10.3389/fimmu.2020.00211

Zanger UM, Schwab M. 2013. Cytochrome P450 enzymes in drug metabolism: regulation of gene expression, enzyme activities, and impact of genetic variation. Pharmacology and Therapeutics 138:103-141.

Zhuang $\mathrm{Y}$ et al. 2015. Evaluation of disease-mediated therapeutic protein-drug interactions between an anti-interleukin-6 monoclonal antibody (sirukumab) and cytochrome P450 activities in a phase 1 study in patients with rheumatoid arthritis using a cocktail approach. The Journal of Clinical Pharmacology 55:1386-1394. 